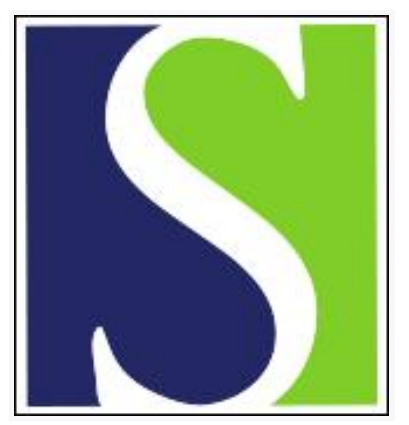

Scand J Work Environ Health 2001;27(4):279-286

https://doi.org/10.5271/sjweh.615

Issue date: Aug 2001

Burnout and engagement at work as a function of demands and control

by Demerouti E, Bakker AB, de Jonge J, Janssen PPM, Schaufeli WB

Affiliation: University of Nijmegen, Department of Work \& Organizational Psychology, Postbox Office 9104, 6500 HE Nijmegen, Netherlands. E.Demerouti@psych.kun.nl

The following articles refer to this text: 2006;32(5):339-348;

2008;34(5):345-355

Key terms: absorption; burnout; burnout at work; dedication; demand-control model; engagement; engagement at work; vigor

This article in PubMed: www.ncbi.nlm.nih.gov/pubmed/11560342 


\title{
Burnout and engagement at work as a function of demands and control
}

\author{
by Evangelia Demerouti, PhD, ${ }^{1,2}$ Arnold B Bakker, PhD, ${ }^{3}$ Jan de Jonge, PhD, ${ }^{3}$ Peter PM Janssen, PhD, ${ }^{4}$ \\ Wilmar B Schaufeli, $P h D^{3}$
}

\begin{abstract}
Demerouti E, Bakker AB, de Jonge J, Janssen PPM, Schaufeli WB. Burnout and engagement at work as a
\end{abstract} function of demands and control. Scand J Work Environ Health 2001;27(4):279—286.

\begin{abstract}
Objectives The present study was designed to test the demand-control model using indicators of both health impairment and active learning or motivation.

Methods A total of 381 insurance company employees participated in the study. Discriminant analysis was used to examine the relationship between job demands and job control on one hand and health impairment and active learning on the other.

Results The amount of demands and control could be predicted on the basis of employees' perceived health impairment (exhaustion and health complaints) and active learning (engagement and commitment). Each of the four combinations of demand and control differentially affected the perception of strain or active learning. Job demands were the most clearly related to health impairment, whereas job control was the most clearly associated with active learning.

Conclusions These findings partly contradict the demand-control model, especially with respect to the validity of the interaction between demand and control. Job demands and job control seem to initiate two essentially independent processes, and this occurrence is consistent with the recently proposed job demands-resources model.
\end{abstract}

Keywords absorption, burnout, dedication, demand-control model, engagement, vigor

The demand-control model $(1,2)$ is a theoretical model that attempts to provide insight into the relationships between psychosocial work characteristics on one hand and health and motivation on the other. Partly because of its elegant simplicity, the model has stimulated several scientific studies $(3,4,5)$. It looks for the determinants of workers' health and motivation in the interaction of two psychosocial job characteristics, namely, the "psychological demands" corresponding to psychological stressors present in the work environment (eg, high time pressure, difficult and mentally taxing work) and "decision latitude" (or "job control") comprising the worker's authority to make decisions on the job ("decision authority") and the breadth of skills used by the worker on the job ["skill discretion" (6)] (figure 1).
The demand-control model is based on two central assumptions, as reflected by diagonals $\mathrm{A}$ and $\mathrm{B}$ in figure 1. The first assumption (diagonal A) is that psychological strain (such as chronic fatigue, anxiety, and cardiovascular complaints) is particularly caused by the combination of high psychological demands and low decision latitude (quadrant 1), while the opposite, lack of strain, can be found in a job with low psychological demands and much decision latitude (quadrant 3). The second important assumption (diagonal B) is that work motivation, as well as learning and development opportunities, occur if job demands are high (but not overwhelming) and decision latitude is high (quadrant 2). The opposite type of work situation occurs in a job in which neither job demands nor decision latitude is

1 Carl von Ossietzky Universität Oldenburg, Department of Work \& Organizational Psychology, Oldenburg, Germany.

2 University of Nijmegen, Department of Work \& Organizational Psychology, Nijmegen, The Netherlands.

3 Utrecht University, Department of Social and Organizational Psychology, Utrecht, The Netherlands.

4 University of Maastricht, Department of Health Studies, Maastricht, The Netherlands.

Reprint requests to: Dr Evangelia Demerouti, University of Nijmegen, Department of Work \& Organizational Psychology, Postbox Office 9104, 6500 HE Nijmegen, The Netherlands. [E-mail: E.Demerouti@ psych.kun.nl] 


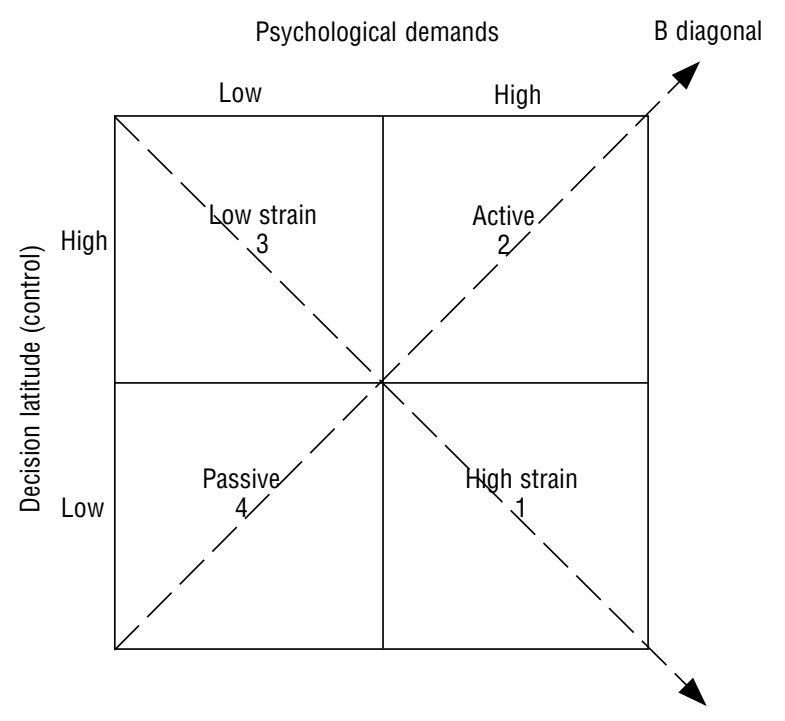

A diagonal

Figure 1. The demand-control model [source: Karasek (2)].

very pronounced (quadrant 4). This "passive" work situation is characterized by a decrease in work activities and "negative learning" - a gradual loss of acquired skills.

Recent reviews of the model contend that the demand-control model is appropriate for further investigation since it can predict health and, to a less extent, motivational and productivity outcomes $(3-5,7-9$,). However, the "active-passive" dimension of the model has been underutilized in organizational research (10). Only a few studies provide some evidence for the active-passive dimension of the model (11-14). Studies measuring both strain and motivation or active learning find stronger support for the model than do those restricted to strain consequences (15).

One possible reason for the lack of attention to the active-passive hypothesis may be that most of the interest in the model originated in the field of epidemiology, with cardiovascular diseases as the main form of strain $(7,8)$. Another reason may be that the $\mathrm{B}$ diagonal ["motivation for learning new behavior patterns" (6)] is hard to operationalize as an independent psychological construct, since it may be conceptually confounded by the job characteristic skill discretion (3).

According to Karasek (1), strain and learning are two, more or less, independent phenomena, and consequently no attempts have been made to integrate the two assumptions in the model. When, for example, job control is high and job demands are low, we should expect low strain, but nothing is explicitly said about the level of motivation. Demerouti et al $(16,17)$ have argued and shown that, when job resources are high, we should expect motivation in the form of engagement, independ- ently of the level of job demands. Job resources represent a broader category of "positive" features of the work environment than job control in the demand-control model. Applied to the demand-control model, this statement would mean that the low strain quadrant is not only related to diminished health impairment, but also to motivation and active learning.

The aim of our study was thus to test the demandcontrol model with special attention to the active-passive hypothesis and to integrate the strain and active learning hypotheses. Specifically, we attempted to predict employees' levels of job demands and job control using stress reactions (burnout, health complaints), but also indicators of active learning (engagement, commitment). In addition, we used an alternative statistical technique, which allows for a different perspective of the predictions of the demand-control model and an examination of the postulated interaction.

\section{Burnout and engagement}

The concept of burnout that was initially relevant only to working with people has recently been expanded towards all other professions and occupational groups (18, 19). Based on the original instrument to measure human service-related burnout [Maslach Burnout Inventory (20)] a new scale [Maslach Burnout InventoryGeneral Survey (21)] has been developed for use outside the human services. The dimensions of the latter (ie, exhaustion, cynicism, professional efficacy) parallel those of the original inventory (ie, emotional exhaustion, depersonalization, personal accomplishment) in the sense that they are more generic and do not refer to the people one is working with. Exhaustion is measured by items that refer to fatigue, but do not make direct reference to people as the source of such feelings. The items assessing cynicism reflect indifference or a distant attitude towards work in general, not necessarily towards people. Finally, professional efficacy encompasses both social and nonsocial aspects of occupational accomplishments. Psychometric research with the Maslach Burnout Inventory-General Survey demonstrated that the three-factor structure is invariant across occupational groups (19).

A recent development in burnout research is the shift towards its opposite, engagement (22). In the view of Maslach \& Leiter (23), workers have a sense of energetic and effective connection with their work activities (energy, involvement), and they see themselves as able to deal with the demands of their job (professional efficacy). Bakker \& Schaufeli (24) partly agree with their description and defined engagement as a positive, fulfilling, work-related state of mind that is characterized by vigor, dedication, and absorption. Rather than a momentary and specific state, engagement refers to a 
more persistent and pervasive affective-motivational state that is not focused on any particular object, event, individual, or behavior. Vigor is characterized by high levels of energy and mental resilience while working, the willingness to invest effort in one's work, and persistence even in the face of difficulties. Dedication is characterized by a sense of significance, enthusiasm, inspiration, pride, and challenge. Absorption is characterized by being fully concentrated and engrossed in one's work, whereby time passes quickly. Bakker \& Schaufeli (24) found evidence for the psychometric quality (ie, internal consistency, factorial validity) of the engagement construct and the independence of the burnout and engagement dimensions.

\section{Present study}

Our study was designed to test the job strain and active learning hypotheses generated by the demand-control model $(1,2)$. Insurance company employees were chosen for this purpose. The sample was suitable for testing the model for several reasons. First, because of the different types of tasks and specialties, insurance employees are a relatively heterogeneous group as far as their work characteristics are concerned, which implies that there is considerable variance in their job demand and control. Second, the group chosen had relatively long job tenure. Since the demand-control model refers to chronic stressors $(2,25)$, the effect of such stressors is most obvious for job holders with long experience in their current job.

A special feature of the study was not only the measurement of psychological strain but also that of indicators of active learning and motivation. As strain and active learning are not one-dimensional, we operationalized them through the use of several indicators. For that purpose, burnout and engagement were included. However, burnout is a complex syndrome that consists of an orthodox stress reaction (exhaustion), as well as of an attitudinal component (cynicism and lack of efficacy) that is closely linked to motivation. In other words, when workers are cynical and do not feel efficacious, they may not be willing to learn actively. In addition psychosomatic complaints on one hand and engagement (including vigor, dedication, and absorption) and commitment on the other were included as indices of strain and active learning, respectively.

\section{Subjects and methods}

\section{Sample and procedure}

Altogether, 381 employees from an insurance company participated in the study (response rate $=61 \%$ ). Most of the respondents were men $(66 \%)$. The mean age of the group was 40 (SD 10.4) years, and the mean organizational tenure was 12.5 (SD 10.5) years. Twelve percent of the sample had a managerial position. Most of the participants had a full-time job $(64 \%)$. The group was recruited at their job sites after an informative meeting with the personnel department and management. All 624 employees received an informative letter about the study from the management team, together with the questionnaire and a return envelope. The confidentiality and anonymity of the data were emphasized. The participants were kindly requested to fill out the questionnaire at home and to place it in a special box in their department.

\section{Measures}

In this study, psychological job demands refer to the extent to which the work pace is high and the availability of sufficient time to execute the required work. Job demands were measured with five items of the Dutch version of the Job Content Questionnaire (26). The four response categories ranged from 1 "never" to 4 "always". [Example item: "Do you have a lot of work to do?"]

Job control was conceived as the degree to which employees have the freedom to make decisions regarding the work assignment and their work methods. Nine items of the Dutch version of the Job Content Questionnaire (26) were used. The response format was identical to that used for job demands. [Example item: "Do you participate in decisions regarding your work?']

Burnout was measured with the Dutch version (27) of the Maslach Burnout Inventory-General Survey (21). The instrument consists of 16 items that measure the three components of burnout (exhaustion, cynicism and professional efficacy). The items were scored on a 7 -point scale $(0=$ never, $6=$ always $)$. [Example items: "I feel used up at the end of the workday" (exhaustion), "I have become less enthusiastic about my work" (cynicism), and "In my opinion, I am good at my work" (professional efficacy).]

Psychosomatic health complaints refer to the number of psychosomatic symptoms that a person experienced during the year preceding the study. Health complaints were measured with 13 items of a well-validated questionnaire on health complaints (28). Employees could respond using a 4-point scale $(1=$ seldom or never, $4=$ very often). [Example items: "Do you have unpleasant pains on the breast?" and "Do you have headaches?"]

Engagement was assessed with the Utrecht work engagement scale (24). The scale includes 15 items, which measure the three components of engagement (vigor, dedication and absorption). All the items were rated on a 7-point scale ranging from 0 "never" to 6 "always". [Example items: "During my work, I feel vital and strong" (vigor), "I am enthusiastic about my 
Table 1. Means (M), standard deviations (SD), internal consistencies $(\alpha)$ and Pearson correlations of the variables included in this study $(\mathrm{N}=381)$.

\begin{tabular}{|c|c|c|c|c|c|c|c|c|c|c|c|c|}
\hline Variable & M & SD & $\alpha$ & 1 & 2 & 3 & 4 & 5 & 6 & 7 & 8 & 9 \\
\hline 1. Job demands & 2.69 & 0.43 & 0.85 & & & & & & & & & \\
\hline 2. Job control & 2.87 & 0.35 & 0.75 & 0.04 & & & & & & & & \\
\hline 3. Exhaustion & 1.79 & 1.08 & 0.89 & $0.25^{\star \star}$ & $-0.20^{\star \star}$ & & & & & & & \\
\hline 4. Cynicism & 1.49 & 0.94 & 0.74 & $0.11^{\star}$ & $-0.29^{\star *}$ & $0.60^{\star *}$ & & & & & & \\
\hline 5. Personal competence & 4.02 & 0.85 & 0.78 & $0.15^{\star \star}$ & $0.44^{\star *}$ & $-0.18^{\star \star}$ & $-0.30^{\star \star}$ & & & & & \\
\hline 6. Health complaints & 1.44 & 0.37 & 0.86 & $0.13^{\star *}$ & $-0.23^{\text {** }}$ & $0.56^{\star \star}$ & $0.41^{\star \star}$ & $-0.17^{\star \star}$ & & & & \\
\hline 7. Vigor & 3.92 & 0.88 & 0.86 & 0.08 & $0.40^{\star \star}$ & $-0.41^{\star \star}$ & $-0.44^{\star \star}$ & $0.65^{\star \star}$ & $-0.37^{\star \star}$ & & & \\
\hline 8. Dedication & 4.19 & 0.96 & 0.90 & 0.05 & $0.53^{\star \star}$ & $-0.29^{\star \star}$ & $-0.50^{\star \star}$ & $0.69^{\star \star}$ & $-0.28^{\star \star}$ & $0.76^{\star \star}$ & & \\
\hline 9. Absorption & 3.56 & 0.98 & 0.80 & 0.07 & $0.42^{\star \star}$ & $-0.16^{\star \star}$ & $-0.32^{\star \star}$ & $0.52^{\star \star}$ & $-0.18^{\star \star *}$ & $0.73^{\star *}$ & $0.75^{\star \star}$ & \\
\hline 10. Commitment & 3.61 & 0.60 & 0.80 & -0.05 & $0.30^{* *}$ & $-0.36^{\star \star}$ & $-0.44^{\star \star}$ & $0.40^{\star \star *}$ & $-0.24^{\star \star}$ & $0.49^{\star *}$ & $0.59^{\star *}$ & $0.45^{\star *}$ \\
\hline
\end{tabular}

${ }^{\star} P<0.05,{ }^{* *} P<0.01$.

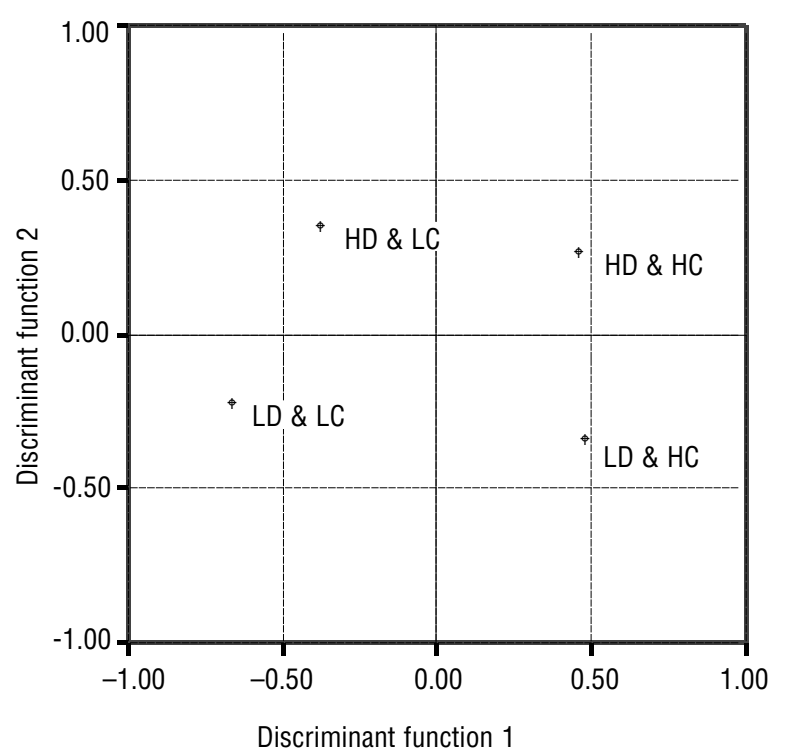

Figure 2. Group centroids for the four combinations of demands and control in a two-dimensional space. LD \& LC = low demands and low control; LD \& HC = low demands and high control; HD \& LC = high demands and low control; $\mathrm{HD} \& \mathrm{HC}=$ high demands and high control.

Table 2. Standardized canonical coefficients for the scales used in the discriminant function analyses $(\mathrm{N}=381)$.

\begin{tabular}{lcc}
\hline & \multicolumn{2}{c}{ Discriminant function } \\
\cline { 2 - 3 } Scales & I & ॥ \\
\hline Dedication & 0.97 & -0.19 \\
Personal competence & 0.82 & 0.35 \\
Vigor & 0.76 & -0.18 \\
Absorption & 0.71 & -0.09 \\
Commitment & 0.52 & -0.24 \\
Cynicism & -0.40 & 0.46 \\
Exhaustion & -0.25 & 0.77 \\
Health complaints & -0.24 & 0.44 \\
\hline
\end{tabular}

job" (dedication), and "Time flies when I am working" (absorption).]

Commitment refers to the relationship of employees to the organization in which they work. It is measured with the 5 items of the affective commitment scale developed by Mowday et al (29). [Example item: "I tell my friends and family that my organization is a pleasant organization to work for" $(1=$ totally disagree, $5=$ totally agree).]

\section{Data analysis strategy}

The strategy followed in the present study was to look for different generalized patterns of health impairment and active learning to indicate the differences between the four combinations of job demands and job control (ie, the four quadrants in figure 1). If these four combinations are related to health impairment and active learning, it should be possible to separate the four quadrants on the basis of the response patterns to questions about health impairment (exhaustion, health complaints) and active learning (engagement, professional efficacy, cynicism, commitment) by means of a discriminant analysis. This form of statistical treatment of the problem offers the advantage of making use of the common variance of the individual aspects or items of health impairment and active learning and thus ignores singularities that might otherwise blur the picture. If, on the other hand, there is no significant difference in the effects of a combination of job demand and job control, no discrimination based on the reported health impairment and active learning should be possible.

The procedure used yielded the following target groups for the discriminant analysis: low demands and low control (LD \& LC), low demands and high control (LD \& HC), high demands and low control (HD \& LC), and high demands and high control (HD \& HC). After a median split on the measures of job demands and job 
control, low (high) was considered the employees who scored under (above) the mean value of 0 after a $\mathrm{z}$-transformation.

\section{Results}

The means, standard deviations, internal consistencies, and the bivariate correlations of the study variables are presented in Table 1. As can be seen from this table, all the scales had good internal consistency (30), and the pattern of correlations was as expected.

The stepwise discriminant analysis revealed a significant separation of the four groups [Wilk's $\lambda=0.73$, $\left.\chi^{2}(9)=108.92, \mathrm{P}<0.001\right]$. More specifically, two discriminant functions were significant for an optimal discrimination between the four groups. The eigenvalue of the first discriminant function was 0.26 and the canonical correlation was 0.45 . For the second discriminant function, these values were 0.09 and 0.29 , respectively.

As can be seen from the plot of the group centroids in figure 2, the first discriminant function clearly discriminates between the presence and absence of job control, while the second discriminant function separates the two levels of job demands. Overall, $42.1 \%$ of the total sample could be correctly classified; this result indicates that the classification by these discriminant functions is obviously superior to a random assignment based on prior group membership probabilities, which would be only $25 \%$ of the sample (31). The plot of the group centroids showed that job control had been classified more accurately than job demands on the basis of the discriminating measures since the distances between the groups with low and high control (independent of the level of demands) were larger than the distances between the groups with low and high demands.

The standardized canonical coefficients for the scales of health impairment and motivation in the discriminant functions are displayed in table 2. The first canonical variable - discriminating for the presence or absence of control - was characterized by features related to motivation and active learning, including dedication, professional efficacy, vigor, absorption, and commitment. The second canonical variable - separating low job demands from high job demands - was mainly characterized by health impairment, namely, by exhaustion, and by psychosomatic health complaints. Cynicism had almost equally high loadings on both discriminant functions and thus made no contribution to discrimination among the groups. Indeed, the results were identical after the elimination of cynicism.

Since positive values in a discriminant function mean dominance of the respective canonical (or discriminant) variables and negative values represent an underrepresentation of these variables, figure 2 can be interpreted as follows: positive values on the first discriminant function delineate an overrepresentation of motivation and learning, and negative values on this discriminant function indicate an underrepresentation or absence of motivation. Similarly, positive values on the second discriminant function stand for an overrepresentation of health problems, while negative values indicate the absence or underrepresentation of these problems. Specifically, LD \& LC jobs were characterized by an absence of both health impairment and worker motivation (because they were located in the quadrant where both discriminant functions are negative), while LD \& $\mathrm{HC}$ jobs were characterized by the presence of motivation and an absence of health impairment. Furthermore, the distinctive characteristics of HD \& LC jobs were health impairment (positive values on the first discriminant function) and an absence of worker motivation (negative values on the second discriminant function), whereas HD \& HC jobs were characterized by both health impairment and motivation.

Finally, figure 3 shows the proportion of participants classified correctly, as well as the proportion of false classifications. As can be seen, the best prediction was made for job control when job demands were low, and the worst prediction was made for high demands when job control was low. Furthermore, figure 3 shows that the proportion of extremely wrong classifications was relatively low (eg, predicted membership HD \& HC when the jobs were actually characterized by LD \& LC).

\section{Discussion}

Our study shows that positive and negative work experiences are differently predictive of the four combinations of job demands and job control, as proposed by the demand-control model $(1,2)$. Our hypothesis that the amount of demands and control could be predicted on the basis of reported health impairment and active learning was confirmed. By means of a discriminant analysis, we were able to separate the four quadrants of the demand-control model according to the employees' pattern of response to questions about different indicators of health impairment and active learning and not according to that of unique indicators, as is the case with the use of a multivariate analysis of variance. In addition, for more than two groups, "discriminant analysis is preferred because it is computationally more efficient than logistic regression analysis" (32, p 335). In other words, our alternative methodology was successful in detecting the reported combinations of job demands and control on the basis of employees' burnout and engagement. Each of the four combinations of demands and control was differentially related to the experience of strain consequences or motivational outcomes. 
Low demands \& low control

Low demands \& high control
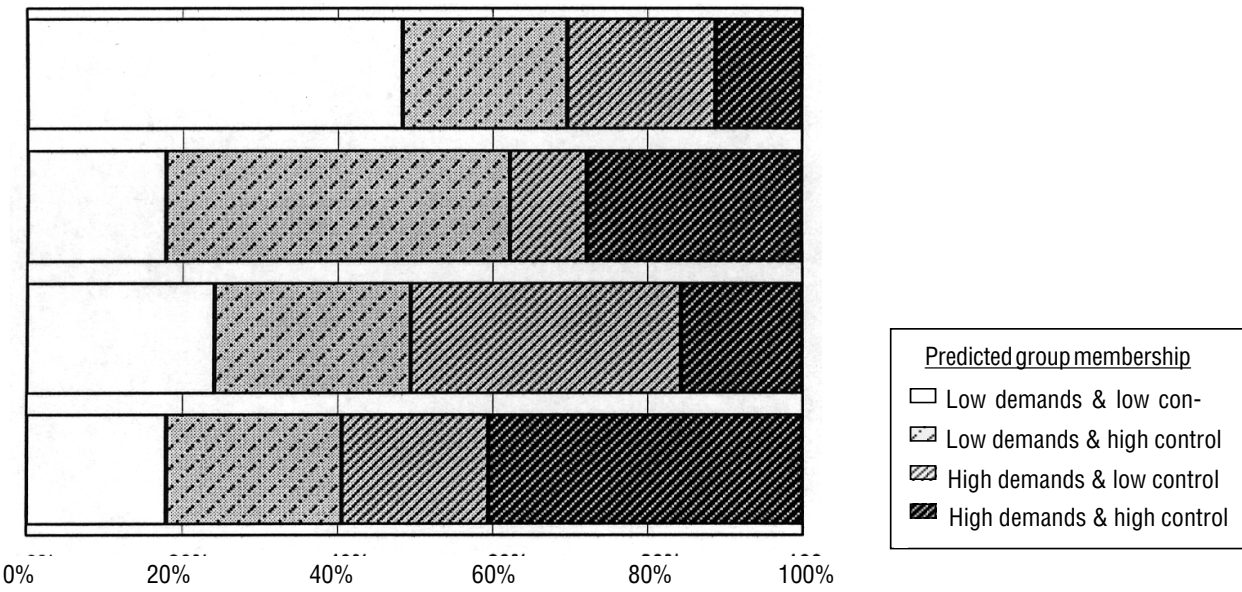

Figure 3. Results of the classification procedure.

The indicators that were responsible for the discrimination between low versus high job control were professional efficacy, vigor, dedication, absorption, and commitment. In other words, the experience of job control is probably responsible for the experience of motivation and learning. Note, however that cynicism (ie, distancing from work) - which was seen as an indicator of low motivation (33) - made no contribution to this discrimination. Thus cynicism is not only strongly (and negatively) related to the conceptual similar constructs, for example, dedication, but is also strongly (and positively) related to the other core burnout component of exhaustion. It therefore justifies the designation of burnout as an affective-motivational syndrome (ie, the existence of one component increases the possibility of the existence of the other component). On the other hand, the discrimination of low versus high job demands was mainly based on employees' levels of exhaustion and health complaints. It seems, in other words, that job demands were the factor most clearly responsible for the development of health impairment.

However, the combination of both discriminant functions gives a more accurate insight into the relationship between demands and control on one hand and positive and negative experiences at work on the other hand. The employees who reported low demands and low control reported both low active learning and little strain, which is in agreement with Karasek's $(1,2)$ predictions. In addition, the job strain hypothesis, referring to a work situation of high demands and low control was also confirmed. The employees who worked under such conditions experienced pronounced strain consequences and low active learning. However, inconsistent with predictions from the demand-control model, employees who reported low demands and high job control (ie, in socalled low strain jobs according to Karasek's terminol- ogy) experienced few strain consequences but scored relatively high on active learning as well. Furthermore, employees in active jobs (high demands and high control) reported not only high motivation but also high levels of strain, a finding also not completely in line with the prediction of the model, since one would expect active learning and average psychological strain in such work environments.

Our study produced some remarkable findings. First, our findings suggest that active jobs may not only lead to increased worker motivation and learning, but also to high strain. This simultaneous existence of both motivation and health impairment in so-called active jobs requires a systematic observation in future studies. It may represent a specific feature of our population, or it might mean that a high level of job demands is linked to health impairment with or without the additional availability of job control. Furthermore, it could also be that, in this group, job demands were in fact too high. If this were the case, much of the energy mobilized by job demands could not be translated into effective problem solving (ie, job control), the consequence being much residual strain (2). This possibility is also consistent with the ideas of Warr's Vitamin Model (34), which assumes that neither too many nor too few demands are good for employees.

A second remarkable finding is that low-strain jobs may not only lead to reduced health impairment, but also to the experience of active learning. This finding also contradicts the prediction of the demand-control model and may be due to method artifacts (motivated employees assessing their jobs as less demanding), or it may represent another point of view in the interpretation of job demands (ie, demands are a troublesome aspect of the job and require additional effort from the employee in order to be fulfilled). According to our findings, high 
job demands are linked to an overrepresentation of strain (independent of job control), whereas high job control is related to an overrepresentation of active learning (independent of the level of demands). In other words, job control seems to be an insufficient buffer that could temper the effects of job demands, or job demands seem to have an overwhelming character for employees. Consequently, the results of our study raise the necessity of additional investigation into the specific mechanisms of how high job demands must be to become a challenge (and further lead to motivation and active behavior) and from what level they are overwhelming (and consequently result in health impairment).

These findings generally support the assumption of different ill-health indicators for the distinct combinations of demands and control. Although the discriminating solution was not completely accurate, the correct classifications had the highest frequency, and the extremely wrong classifications had the lowest frequency. More importantly, the combinations of demands and control that were on the active learning diagonal, and clearly represent the interaction effect (LD \& LC and HD \& HC), could be efficiently discriminated from each other. The same applies for the strain diagonal (LD \& $\mathrm{HC}$ and $\mathrm{HD} \& \mathrm{LC}$ ). However, the resulting relationships between job demands and job control on one hand and positive and negative outcomes on the other do not completely confirm the expectations of the demand-control model, but they do confirm the job demands-resources model $(16,17)$. The job demands-resources model states that excessive job demands are primarily related to negative stress reactions, like exhaustion, whereas job resources are mainly related to motivational outcomes, like engagement and professional efficacy. Recent studies with this model have clearly shown that the relationships between job demands and motivational indicators, as well as between job resources and strain are marginal $(16,17)$.

A weakness of our study is that both job characteristics and outcomes were measured with a cross-sectional, self-report questionnaire. In principle, this methodology throws the causality hypothesis into a questionable state. However, several longitudinal studies in this domain have shown that job characteristics, like job demands and job control have causal predominant relationships with health outcomes in such a way that the outcomes tend to occur after job perceptions, rather than vice versa (35). As far as the self-report measures are concerned, the job holder seems to be the most important source to offer information regarding his or her unique job position (36). Other, "objective" methods, such as observers' ratings, appear to be good alternatives, but they also suffer from problems, including observer bias and halo and stereotyping effects (37). Furthermore, common method variance should not have inflated the relationships of the variables, since a confirmatory factor analytic approach, using only a single factor method (38), showed that a method factor could not adequately explain the variance of the study variables. In a similar vein, the two-factor confirmatory factor analytic approach, in which one factor was operationalized by all positively phrased scales (job control, vigor, dedication, absorption, commitment and professional efficacy) and the second factor was operationalized by all negatively phrased scales (job demands, exhaustion, cynicism, and health complaints), revealed that response bias due to item wording was again insufficient in explaining the variance of the variables under study.

An advantage of our study was the inclusion of both positive and negative outcomes of job (re)design with respect to the individual, as recommended by Karasek (2). The results of our study show that, to obtain better insight into the postulated effects of the demand-control model and to find support for the postulated (interaction) effects (15), the inclusion of both positive and negative outcomes is necessary.

In summary, our methodology appeared to be successful in investigating the importance of combinations between job demands and job control in predicting health impairment and active learning or motivation. Health impairment differentiated between low and high demanding jobs, whereas active learning differentiated between jobs allowing low and high job control. Nevertheless, the specific hypotheses of Karasek (1) that are inherent in the demand-control model were only partly confirmed, since the low-strain jobs were filled by employees without health impairments but with motivation, whereas the active jobs included employees with motivation but also reporting health complaints. Future studies should therefore set out the interplay of the two core assumptions of the demand-control model in combination with longitudinal research designs and focus more explicitly on the motivation or active learning hypothesis.

\section{Acknowledgments}

This research is part of the concerted research action on "Fatigue at Work" granted by The Netherlands Organization for Scientific Research (NWO), 580-02-202.

We thank Michiel Baldal and Marco van Putten for their help with data collection.

\section{References}

1. Karasek RA. Job demands, job decision latitude and mental strain: implications for job redesign. Adm Sci Q 1979;24: 285-308.

2. Karasek RA. Demand/control model: a social, emotional, 
and psychological approach to stress risk and active behaviour development. In: Stellman JM, editor. Encyclopaedia of occupational health and safety. Geneva: International Labour Office, 1998:34.6-34.14.

3. De Jonge J, Kompier MAJ. A critical examination of the demands-control-support model from a work psychological perspective. Int J Stress Manage 1997;4:235-58.

4. Van der Doef M, Maes S. The job demand-control(-support) model and physical health outcomes: a review of the strain and buffer hypotheses. Psychol Health 1998;13:909-36.

5. Van der Doef M, Maes S. The job demand-control(-support) model and psychological well-being: a review of 20 years empirical research. Work Stress 1999;13:87-114.

6. Karasek RA, Theorell T. Healthy work: stress, productivity and the reconstruction of working life. New York (NY): Basic Books, 1990.

7. Kristensen TS. The demand-control-support model: methodological challenges for future research. Stress Med 1995; $11: 17-26$.

8. Kristensen TS. Job stress and cardiovascular disease: a theoretical critical review. J Occup Health Psychol 1996;1:246-60.

9. Schnall PL, Landsbergis PA, Baker D. Job strain and cardiovascular disease. Annu Rev Public Health 1994;15:381- 411.

10. Theorell T, Karasek RA. Current issues relating to psychological job strain and cardiovascular disease research. J Occup Health Psychol 1996;1:9-26.

11. De Jonge J, Dollard MF, Dormann C, Le Blanc PM, Houtman ILD. The demand-control model: specific demands, specific control, and well-defined groups. Int J Stress Manage 2000;7, 269-87.

12. Karasek RA. Job socialization and job strain: the implications of 2 related psychosocial mechanisms for job design. In: Gardell B, Johansson G, editors. Man and working life. Chichester (UK): Wiley, 1981:75-94.

13. Landsbergis PA, Schnall PL, Deitz D, Friedman R, Pickering T. The patterning of psychological attributes and distress by 'job strain' and social support in a sample of working men. J Behav Med 1992;15:379—405.

14. Meijman TF, Ulenbelt P, Lumens ME, Herber RF. Behavioral determinants of occupational exposure to chemical agents. J Occup Health Psychol 1996;1:85—91.

15. De Rijk AE, Le Blanc PM, Schaufeli WB, De Jonge J. Active coping and need for control as moderators of the job demand-control model: effects on burnout. J Occup Organ Psychol 1998;71:1-18.

16. Demerouti E, Bakker AB, Nachreiner F, Schaufeli WB. A model of burnout and life satisfaction among nurses. J Adv Nurs 2000;32:454-64.

17. Demerouti E, Bakker AB, Nachreiner F, Schaufeli WB. The job demands-resources model of burnout. J Applied Psychol. In press.

18. Taris TW, Schreurs PJ, Schaufeli WB. Construct validity of the Maslach burnout inventory — general survey: a twosample examination of its factor structure and correlates. Work Stress 1999;13:223-37.

19. Schutte N, Toppinnen S, Kalimo R, Schaufeli WB. The factorial validity of the Maslach burnout inventory - general survey (MBI-GS) across nations and occupations. J Occup Organ Psychol 2000;73:53-66.

20. Maslach C, Jackson SE. Maslach burnout inventory. 2nd ed. Palo Alto (CA): Consulting Psychologists Press, 1986.

21. Schaufeli WB, Leiter MP, Maslach C, Jackson SE. The
Maslach burnout inventory — general survey. In: Maslach C, Jackson SE, Leiter MP, editors. Maslach burnout inventory [manual]. 3rd ed. Palo Alto (CA): Consulting Psychologists Press, 1996.

22. Maslach C, Schaufeli WB, Leiter MP. Job burnout. Annu Rev Psychol 2001;52:397-422.

23. Maslach C, Leiter MP. The truth about burnout: how organizations cause personal stress and what to do about it. San Francisco (CA): Jossey-Bass, 1997.

24. Bakker AB, Schaufeli WB. De Utrechtse bevlogenheidsschaal: UBES [The Utrecht engagement scale: UBES]. Utrecht (The Netherlands): Utrecht University, Department of Social and Organizational Psychology, 1999.

25. Levi L, Bartley M, Marmot M, Theorell T, Karasek RA, Siegrist J, et al. Stressors at the workplace: theoretical models. In: Schnall PL, Belkić K, Landsbergis P, Baker D, editors. The workplace and cardiovascular disease. Philadelphia (PA): Hanley \& Belfus, 2000:69-106. Occupational medicine: state of the art reviews, vol 15.

26. Karasek RA, Brisson C, Kawakami N, Houtman I, Bongers $\mathrm{P}$, Amick B. The Job content questionnaire (JCQ): an instrument for internationally comparative assessments of psychosocial job characteristics. J Occup Health Psychol 1998;3:322-55.

27. Schaufeli WB, Van Dierendonck D. Maslach burnout inventory: Nederlandse versie [Maslach burnout inventory: Dutch version]. Lisse (The Netherlands): Swets Zeitlinger, 2000.

28. Joosten J, Drop MJ. De betrouwbaarheid en vergelijkbaarheid van drie versies van de VOEG [Reliability and comparability of three versions of the VOEG]. Gezondheid en Samenleving 1987;8:251-65.

29. Mowday RT, Steers RM, Porter LW. The measurement of organizational commitment. J Vocat Behav 1979;14:224- 47.

30. Cortina JM. What is coefficient alpha? An examination of theory and applications. J Appl Psychol 1993;78:98-104.

31. Tabachnik BG, Fidell LS. Using multivariate statistics. 2nd ed. New York (NY): Harper Collins Publishers, 1989.

32. Sharma S. Applied multivariate techniques. New York (NY): Wiley, 1996.

33. Schaufeli WB, Enzmann D. The burnout companion to study and practice: a critical analysis. London: Taylor \& Francis, 1998.

34. Warr PB. Work, unemployment and mental health. Oxford: Oxford University Press, 1987.

35. Buunk BP, de Jonge J, Ybema JF, De Wolff CJ. Psychosocial aspects of occupational stress. In: Drenth PJD, Thierry $\mathrm{H}$, De Wolff CJ, editors, Handbook of industrial and organizational psychology: vol 2. 2nd ed. Brighton: Psychology Press, 1998:145-82.

36. Frese M, Zapf D. On the importance of the objective environment in stress and attribution theory. J Organ Behav 1999;20:761-6.

37. De Jonge J, Van Breukelen GJP, Landeweerd JA, Nijhuis FJN. Comparing group and individual level assessments of job characteristics in testing the job demand-control model: a multilevel approach. Hum Relat 1999;52:95-122.

38. McFarlin DB, Sweeney PD. Distributive and procedural justice as predictors of satisfaction with personal and organizational outcomes. Acad Manage J 1992;35:626-37.

Received for publication: 7 August 2000 